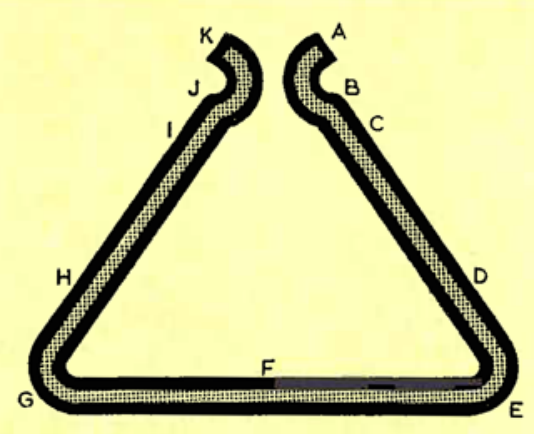

Fig. 8 The variation in thickness of gold deposit on a barrel plated phosphor bronze spring contact

$\begin{array}{lllllllllllll}\text { Point } & \text { A } & \text { B } & \text { C } & \text { D } & \text { E } & \text { F } & \text { G } & \text { H } & \text { I } & \text { J } & \text { K } \\ \begin{array}{l}\text { Thickness } \\ \text { (internal) } \mu \mathrm{m}\end{array} & 10 & 8 & 8 & 10 & 7 & 12 & 7 & 10 & 8 & 11 & 11 \\ \begin{array}{l}\text { Thickness } \\ \text { (external) } \mu \mathrm{m}\end{array} & 10 & 9 & 7 & 8 & 8 & 9 & 8 & 8 & 7 & 9 & 11\end{array}$

areas. Mixed loads should also be avoided, as different articles will become plated with different thicknesses of deposit; larger articles, in particular, generally receive greater thicknesses.

Deposit thickness distribution in barrel plating is a special case. Generally the coating thickness variation tends to increase as the deposit thickness increases. Figure 8 shows the metal distribution on a typical barrel plated spring contact. For a proper assessment of the mean thickness of the deposit on articles in a barrel load, the testing of at least 15 samples may be necessary, while 20 to 25 articles may well be required for the calculation of the standard deviation.

\section{Gold Reflectors for Lasers}

The many applications of high-power-density lasers have introduced more severe requirements for optical reflectors. In particular there is now a need for reflective surfaces consisting of high purity metals free from even minute defects such as inclusions or voids which might lead to damage. The preparation of such high quality optical surfaces by a newly developed type of precision machining of an electrodeposited layer of gold is being actively pursued at the Oak Ridge Plant in Tennessee, and a progress report from there by F. B. Waldrop, M. J. Bezik, W. E. Tewes and R. C. Waldrop gives some details of the procedures adopted (Applied Optics, 1975, 14, (8), 1783-1787).

The high quality machined surface is obtained by using special machine tools and tool bits that are ground from single crystal diamond, the process being referred to as diamond turning. As yet only copper, silver, gold and aluminium are suitable for machining by this method, but a more refractory metal such as beryllium (to reduce weight) or molybdenum (to achieve a low coefficient of expansion) is desirable for the substrate. These metals are of course generally characterised by a tenacious oxide film that militates against adhesion of
An important factor in thickness distribution is a smooth rolling movement during the plating operation. Complicated shapes cause a shielding effect and large thickness variations, especially when the plating times are short (4). The form of the internal surface of the barrel, the rate of rotation, and the depth of the load are also significant.

\section{Benefits from Good Design}

The question of design for gold plating industrial products has been somewhat neglected when compared with the amount of attention which has been given to designing articles intended for plating with base metals. Even in the latter case, however, much more could be done. Yet the benefits which can accrue from proper attention to design-metal savings, the reduction of rejects, and economies of production costs-generally are of outstanding importance in the case of gold plating.

The adoption of some of the measures which have been outlined will certainly involve some trouble, and possibly a little expense, but these will be vastly exceeded by the resulting gains.

\section{References}

1 G. H. Keulegan, "Hydrodynamics of Cathode Films" F. Res. Nat. Bur. Stand., 1951, 47, (3), 156-169

2 R. H. Rousselot, "Current Distribution over ThreeDimensional Electrodes", Trans. Inst. Metal Finish., 1964, 42, 100-106

3 W. H. Safranek and A. A. Underwood, "Influence of Design on Electroplating of Zinc Diecastings", American Zinc Institute, New York, 2nd Edn., 1966

4 A. W. Wallbank and D. N. Layton, "The Plating of Screw Threads", Trans. Inst. Metal Finish., 1955, 32, 308-335

an electrodeposit. This disadvantage has been overcome by a preliminary vapour deposition process-ion plating-in which an initial very thin but adherent coating of aluminium is produced, upon which a conventional electrodeposit can be applied. This process is carried out in an argon atmosphere under a pressure of a few microns. The surface to be treated is first cleaned by sputtering with argon ions to remove any oxide film. Aluminium ions are then accelerated towards the substrate by the high voltage with such velocity that they penetrate the surface, so ensuring excellent adhesion to the most refractory of metals.

Electrodeposition on to this preliminary coating can then be carried out and good adhesion can be achieved, using standard processes. The most suitable electrolyte has been found to be the citrate-based acid cyanide bath, and deposits from this electrolyte showed no voids under the microscope, a purity of 99.98 per cent, and a density equivalent to that of solid gold.

These gold surfaces, diamond turned to a mirror finish, gave reflectivities of approximately 99.3 per cent at $10.6 \mu \mathrm{m}$ in the as-machined condition, an outstanding quality in terms of reflectivities. 